\title{
OS MODOS DE ENGAJAMENTO DO LEITOR DE GRANDE SERTÃO: VEREDAS EM QUADRINHOS
}

\section{Renata Mancini ${ }^{\star}$}

Resumo: O universo aberto pela obra Grande sertão: veredas, de Guimarães Rosa, e seu lugar de marco da literatura brasileira fazem do projeto de sua adaptação para quadrinhos uma aventura que desperta atenção e curiosidade. Quais os caminhos a serem tomados para a construção do roteiro e quais as soluções encontradas para recriar, de modo geral ou em parte, o projeto enunciativo dessa obra contundente? Propomos a análise da adaptação de mesmo título feita por Rodrigo Rosa (arte) e Eloar Guazzelli (roteiro). Procuraremos explicitar algumas estratégias e escolhas dos adaptadores para entender os efeitos de sentido buscados na obra em quadrinhos em sua relação com o romance.

Palavras-chave: Grande sertão: veredas. Tradução intersemiótica. Linguagem dos quadrinhos.

\section{INTRODUÇÃO}

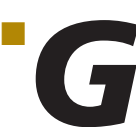

rande sertão: veredas, de João Guimarães Rosa, romance reconhecido como uma das grandes obras da literatura brasileira e mundial, explora caminhos de expressão da língua portuguesa no limiar entre a prosa e a poesia, fundando um lugar em que a tradição oral empresta sua fluência para a construção de um mundo escorregadio, um mundo complexo de opostos irmanados em uma trama densa ambientada no sertão. Uma experiência que se mostra pela ótica do movimento, de seu desenrolar miúdo, constante, caudaloso, profundo:

Por que era que eu estava procedendo à-toa assim? Senhor, sei? O senhor vá pondo seu perceber. A gente vive repetido, o repetido, e, escorregável, num 
mim minuto, já está empurrado noutro galho. Acertasse eu com o que depois sabendo fiquei, para de lá de tantos assombros... Um está sempre no escuro, só no último derradeiro é que clareiam a sala. Digo: o real não está na saída nem na chegada: ele se dispõe para a gente é no meio da travessia (ROSA, 1986, p. 51-52).

O sertão se presta a Riobaldo, narrador-personagem principal, para falar de sua vida pelo ângulo de uma memória construída como espessura do vivido. Ao esmaecer a demarcação entre as vozes do narrador e do personagem - o que em termos semióticos seria a suspensão da demarcação nítida entre as posições de narrador e interlocutor pela construção de um sincretismo actancial (FIORIN, 1999, p. 104) - o narrado se dá ao mesmo tempo como perspectiva do já conhecido e do desenrolar miúdo da experiência em seu transcorrer. O início da obra é marcado com um travessão que mistura esses pontos de vista em uma memória viva, uma "memória-acontecimento [que] mais do que a memória do acontecido se exacerba e toma posse do sujeito para que ele se apresente num espaço propício às experiências sensiveis" (DISCINI, 2017, p. 86).

Essa espessura do vivido se desenrola a partir da conversa do jagunço Riobaldo e o homem da cidade, ali também sincretizado como narratário e interlocutário ao mesmo tempo. Riobaldo conta suas aventuras no sertão pela ótica de quem as vivencia (o interlocutor) e, apesar de saber de antemão o desfecho da história (como narrador), leva seu interlocutor a experienciar com ele as angústias e a tensão que vai crescendo no desenrolar da narrativa, pavimentada com subentendidos, alusões; "não-ditos" que dizem, argumentos por inferência, que acabam por desenhar um subterrâneo dos fatos narrados de forte ambiência passional.

Esse subterrâneo passional é o principal lugar de Diadorim no romance, seu amigo de aventuras do sertão, que nos é apresentado pela primeira vez, misteriosamente, como a pessoa cuja importância se resume no fato de que é dela a imagem que lhe vem à mente no momento da morte:

Concebi que vinham, me matavam. Nem fazia mal, me importei não. Assim, uns momentos, ao menos eu guardava a licença de prazo para me descansar. Conforme pensei em Diadorim. Só pensava era nele. Um joão-de-barro cantou. Eu queria morrer pensando em meu amigo Diadorim, mano-oh-mão, que estava na Serra de Pau-d'Arco, quase na divisa baiana, com nossa outra metade dos sô-candelários... Com meu amigo Diadorim, me abraçava, sentimento meu ia-voava reto para ele... Ai, arre, mas: que esta minha boca não tem ordem nenhuma. Estou contando fora, coisas divagadas (ROSA, 1986, p. 13).

A ambiguidade de seus sentimentos por Diadorim é a tensão que dirige toda a narração e que abre no romance sua dimensão existencial. A obra toda marca opostos, mas não para deixá-los transparecer como tal, mas para embaralhá-los no devir da vida no sertão, para que se mostrem juntos, irmanados: o bem e o mal; deus e o diabo; vida e morte etc. O universo escorregadio da ambiguidade e a maleabilização axiológica, paradoxalmente, se assentam como base sobre a qual a história ganha corpo.

Do sertão múltiplo e uno ao mesmo tempo irradia a narrativa de um universo regional que está posto para falar de questões existenciais. Como marca Antônio 
Candido, o "grande milagre é a ambiguidade suprema de partir do romance regionalista para falar de questões universais"1.

A vasta fortuna crítica da obra não deixa dúvidas sobre a importância da linguagem como fundadora desse universo labiríntico do sertão e ao mesmo tempo sua dimensão existencial profunda. A fala do jagunço, permeada por expressões locais e construída com neologismos, cujo uso prodigioso chega a ser definido como a invenção de um idioma próprio da obra, abre uma dimensão poética e erige o simulacro do sertão como um laboratório da experiência humana. Sobre a força dos simulacros, Greimas (2014, p. 238, grifos do autor) destaca que

[...] a construção de simulacros, desses objetos imaginários que o sujeito projeta para fora de si e que, mesmo sem ter qualquer fundamento intersubjetivo, determinam, de maneira eficaz, o comportamento intersubjetivo considerado como tal.

O universo aberto pela obra e seu lugar de marco da literatura brasileira fazem do projeto de sua adaptação para quadrinhos uma aventura que desperta atenção e curiosidade. Quais os caminhos a serem tomados para a construção do roteiro e quais as soluções encontradas para recriar, de modo geral ou em parte, a proposta de uma obra contundente como Grande sertão: veredas?

\section{A ADAPTAÇÃO COMO PROCESSO DE TRADUÇÃO INTERSEMIÓTICA}

Além de mudar os modos de circulação e penetração de obras literárias, as adaptações para quadrinhos são práticas de tradução intersemiótica que, por si só, ocupam lugar privilegiado para uma análise que procure encontrar parâmetros de reflexão sobre o diálogo ou aproximação de diferentes linguagens.

Formulada nos termos de uma tradução intersemiótica, a adaptação passa a ser encarada como uma recriação de um projeto enunciativo, a partir de alguns critérios, visando a manutenção de alguma identidade da obra de partida na obra de chegada.

Em nossa formulação, o que se traduz é o projeto enunciativo de uma obra: as escolhas e as estratégias das quais o enunciador lança mão no processo de textualização visando seu fazer persuasivo em relação ao fazer interpretativo de um enunciatário que ele prevê no próprio modo de enunciar.

Trocando em miúdos, de uma obra emana uma voz que diz o que diz de um certo modo. Da maneira como a obra se mostra, se enuncia, depreendemos o perfil do "para quem" ela se dirige. Estes são, respectivamente, o enunciador e o enunciatário (cf. GREIMAS; COURTÉS, 2008). O projeto enunciativo é esse "espírito da obra", esse conjunto de estratégias que determina o modo como o objeto semiótico estabelecerá uma tensão entre enunciador e enunciatário, a partir da dinâmica entre o fazer persuasivo de um e o interpretativo do outro.

A questão central é definir nessa tensão o papel do tradutor/adaptador: seu fazer interpretativo como enunciatário da obra de partida (o romance, no caso) modula o fazer persuasivo implicado em suas escolhas na obra de chegada (a HQ) que, por sua vez, será interpretado por um novo perfil de leitor, um novo enunciatário. Nessa tensão reside a centralidade do fazer interpretativo.

1 Entrevista concedida por Antônio Cândido sobre a obra de Guimarães Rosa. Disponível em: https://www.youtube.com/ watch?v=VekkcAyxVdA. Acesso em: 9 abr. 2019. 
Ao procurarmos entender a tradução intersemiótica em sua processualidade, temos que nos debruçar sobre o fazer persuasivo do enunciador, que estabelece não apenas caminhos de interpretação para o enunciatário, mas também modos de interação sensivel com a obra, o que chamamos de engajamento sensivel.

As estratégias de disposição dos elementos de conteúdo e expressão ${ }^{2}$ ficam subjugadas aos modos de engajamento sensivel, na medida em que há uma cifra tensiva que lhes é peculiar. Nesse sentido, entendemos que toda obra se estabelece em um arco tensivo (um arco de modulações sensíveis), a partir do qual são dispostos - pelo enunciador - momentos tônicos ou átonos, inflexões, efeitos de aceleração/tonicidade, em contraposição aos de desaceleração e atonia, que acabam por determinar uma interface sensível do leitor com a obra.

Cabe, portanto, entender o que se constitui como mecanismo de aceleração/ desaceleração tanto no plano de expressão como no de conteúdo, ou mais importante ainda, o que modula o andamento (ZILBERBERG, 2011) do processo de semiose estabelecido entre os planos.

Propomos revisitar o conceito de catálise (HJELMSLEV, 1975), do modo como foi trazido ao bojo da teoria por Greimas e Courtés (2008, p. 54-55):

Catálise é a explicitação dos elementos elípticos ausentes na estrutura de superficie. É um procedimento que se realiza com o auxílio dos elementos contextuais manifestados e mediante as relações de pressuposição que entretêm com os elementos implícitos.

Tomando por base a centralidade do andamento na concepção geral de uma obra, como nos propõe Zilberberg (2006, p. 168) quando diz que "o andamento é senhor, tanto de nossos pensamentos, quanto de nossos afetos" procuramos definir uma dinâmica de acelerações e desacelerações, a partir do operador catálise.

A demanda maior ou menor por catálises, definida pelo modo de enunciar, é o que vai determinar esses momentos de maior ou menor aceleração, ou maior ou menor tonicidade, que definirão o arco tensivo de uma obra. Quanto mais catálises o texto pedir ao enunciatário, mais acelerado e tônico é o que se apresenta. Quanto menos catálises, ou seja, quanto mais explícito for o encadeamento sintagmático proposto, mais desacelerado e átono é o que se apresenta. Fizemos já uma discussão mais detalhada sobre o assunto em outro artigo (MANCINI; ALT, 2013), tratando, inclusive, das potencialidades do requadro nesse manejo rítmico da leitura.

Nas teorizações sobre quadrinhos, apesar de não se mencionar o termo catálise, é fartamente discutida a questão da gestão rítmica de seus elementos de composição. Thierry Groensteen (2015, p. 55) explica de maneira clara a centralidade do ritmo inerente aos caminhos de leitura e interação nos quadrinhos, ao dizer que se trata de

[...] uma leitura cadenciada, uma operação ritmada pelo cruzamento dos quadros. Seu discurso tem a particularidade de ser descontínuo, elíptico, agitado. Cada novo quadro precipita a narrativa e, simultaneamente, a contém. O requadro é o agente dessa dupla manobra de progressão/retenção.

É claro que, ao trazermos o conceito de catálise para pensar o ritmo no universo dos quadrinhos a partir do manejo do andamento, sabemos que não ire-

2 Expressão é em algumas correntes denominada "forma". 
mos contribuir com o entendimento das especificidades implicadas na construção de elipses de conteúdo e lacunas de expressão que conferem identidade à linguagem e que já são fartamente e bem melhor discutidas por especialistas. Nossa ambição é tão somente desvelar um mecanismo geral subjacente a esses fenômenos específicos, procurando, eventualmente, mostrar o que de comum eles podem ter para que, com esse fio único, seja mais fácil entrever como diferentes elementos da composição da linguagem se relacionam.

Quando dizemos que quanto maior as lacunas (mais demandas de catálise), maior a aceleração prevista, e vice-versa, pode parecer, à primeira vista, que estamos nos contrapondo à proposta de Daniele Barbieri (2017, p. 216), quando discute sobre a velocidade de leitura:

Sem dúvida, uma vinheta grande e complexa requer um tempo de leitura maior que uma vinheta de dimensões e complexidade normais em relação ao contexto da história; $e$ isso também pode ocorrer em certas situações com uma vinheta menor que o normal de conteúdo visualmente pouco claro; uma vinheta com diálogos extensos requer um tempo de leitura maior que uma vinheta com diálogos breves ou sem diálogo.

Sob a ótica que estamos adotando, há questões de diferentes ordens aí postas. No caso específico de diálogos extensos, a velocidade de leitura é menor dada a linearidade do significante verbal-escrito que demanda uma sequencialidade estrita de leitura. Entretanto, o que mais nos interessa é algo que consideramos ser de outra ordem: a menção à "complexidade" da vinheta. É na descrição dessa complexidade que nos parece residir a contribuição do que propomos.

Ela pode se dar tanto quando muita informação é oferecida ao mesmo tempo, em várias camadas, como também toma corpo em um enunciado construído com muita demanda de catálises. Em ambos os casos, dizemos que os elementos - de conteúdo, de expressão ou ambos - são apresentados de modo acelerado, o que demanda um esforço de desaceleração no momento da leitura para que o leitor possa concatenar os fatos de maneira a construir todos os seus liames de coesão. Explicitar os elos sintagmáticos de um enunciado é, para a abordagem tensiva, desacelerar o conteúdo, desdobrando-o na extensidade temporal. Por isso, a leitura requer mais tempo quando um conteúdo é oferecido de forma acelerada, porque ele terá que ser desacelerado para fazer sentido. Estamos, portanto, totalmente em linha com as ideias de Barbieri. Apenas olhamos a questão por ângulos complementares.

Dizemos também que a aceleração é uma estratégia do enunciador de exorbitar a interface sensivel do objeto semiótico, na medida em que tanto a saturação de informação posta abruptamente quanto conteúdos elípticos levam o enunciatário a uma intensidade $e^{3}$, um contato tônico, em primeira instância, que deve ser desacelerado para fazer com que o sentido... faça sentido.

A mesma gestão do andamento pode ser pensada para elementos de expressão. Perspectivas inusitadas, contrastes cromáticos marcantes, diversidade de tamanhos e formatos dos quadros, a distribuição espacial dos quadros na página, de modo a guiar mais ou menos o trajeto da leitura, entre outros, são aspectos que podem ser analisados por essa ótica.

3 Intensidade e extensidade são valências, eixos que determinam um espaço tensivo, organizado pela percepção que transforma cada um dos eixos em profundidades organizadas a partir de um ponto de vista. O eixo da intensidade é desdobrado em andamento e tonicidade; o eixo da extensidade, em espacialidade e temporalidade (cf. FONTANILLE; ZILBERBERG, 2001). 
Quando, por exemplo, Scott McCloud (2008, p. 15) ${ }^{4}$ propõe uma tipologia das lacunas para falar de transições mais suaves ou mais elipticas entre quadros está, sob nossa perspectiva, falando de maior ou menor demanda de catálises, posto num contínuo que vai do mais desacelerado ao mais acelerado - do momento a momento, ação a ação, sujeito a sujeito, cena a cena, aspecto a aspecto, non sequitur.

Não podemos perder de vista que o que está em discussão, ao tratarmos de demandas maiores ou menores de catálise, ou mesmo no caso de uma saturação de informação, é o efeito de aceleração dos elementos constitutivos da obra que modulam o arco tensivo de seu projeto enunciativo, como explicamos anteriormente.

Um enunciado concebido de modo acelerado demanda do leitor que ele se demore mais na leitura, pois ele deve desacelerá-lo para reconstituir os elos de sentido. Uma decorrência direta disso é que o recrudescimento da aceleração constrói saliências perceptivas, momentos tônicos e marcantes que, ao se alternar com "passâncias" átonas, vão construindo um ritmo geral para arco tensivo. Barbieri (2017, p. 216) toca nessa questão quando diz que "o tempo de leitura maior para a vinheta corresponde à sua maior importância no relato e não à sua maior duração relatada; trata-se de um acento narrativo, um modo de destacar o que se conta".

O "acento narrativo" mencionado pode, em nossa visão, ser desdobrado e ampliado em parâmetros específicos, advindos das propostas da semiótica discursiva, revisitados a partir da ótica tensiva, para que se ganhe valor operacional de análise.

Os parâmetros de conteúdo que observamos para traçar o perfil do projeto enunciativo em sua totalidade são os seguintes:

- Foco narrativo: Modo de disposição dos programas narrativos, que podem ser arranjados em teia, em paralelo, de modo sequencial etc., e, principalmente, a hierarquia entre eles, que estabelece um peso diferenciado às diferentes narrativas propostas.

- Dinâmica das perspectivas (ou pontos de vista): O jogo de vozes e os tipos de organização temporal e espacial, isto é, as estratégias de projeção da pessoa, do espaço e do tempo na obra.

- Direcionamento ideológico/axiológico: As escolhas temáticas e figurativas definem uma chave axiológica que pode ser mantida ou subvertida de uma obra para a outra.

Vale, no entanto, frisar que pensamos nesses parâmetros sempre à luz das cifras tensivas que os constituem, o que é o mesmo que dizer que os observamos a partir das modulações do arco tensivo pelo andamento, como explicamos.

O manejo das expectativas também é um fator importante no estabelecimento do arco tensivo da obra. Há as estratégias que se assentam na lógica implicativa (se... então), em que há a manutenção da expectativa para o desfecho de um caminho proposto. Há, por outro lado, aquelas pautadas pela lógica concessiva (embora...), em que uma expectativa inicialmente construída é quebrada (ZILBERBERG, 2007, p. 23). Essas lógicas podem ter alcance mais pontual ou

4 Discutimos a tipologia de McCloud à luz da abordagem tensiva em artigo intitulado "Django livre: tradução intersemiótica do cinema para as histórias em quadrinhos" (COUTINHO; MANCINI, no prelo). 
mais abrangente, dependendo do projeto do enunciador. Há, inclusive, que se destacar que as quebras de expectativa podem ser mais brandas ou mais abruptas, o que também ajuda a modular o perfil do arco tensivo do projeto da obra.

Procuraremos mostrar o valor operacional de algumas dessas proposições na análise a seguir.

\section{GRANDE SERTÃO: VEREDAS EM GUADRINHOS}

$\mathrm{Na}$ esteira das considerações teóricas feitas até aqui, propomos uma análise da adaptação de Grande sertão: veredas para a HQ de mesmo título, adaptada por Rodrigo Rosa (arte) e Eloar Guazzelli (roteiro). Procuraremos explicitar algumas estratégias e escolhas dos adaptadores para entender os efeitos de sentido buscados na obra em quadrinhos em sua relação com o romance.

A apresentação da HQ, curiosamente em um blog especializado para literatura infantil, já traz para primeiro plano a importância da ambiência do sertão e a questão do ritmo acelerado no encadeamento dos programas narrativos quando diz:

Com roteiro do diretor de cinema Eloar Guazzelli, a obra transpõe cenas de batalhas surpreendentes para os quadrinhos, dando um ritmo cinematográfico. $O$ ilustrador Rodrigo Rosa não se limita a retratar as paisagens do sertão, mas explora os seus contrastes, a natureza se torna um elemento narrativo, que compõe o clima do romance gráfico (GRANDE SERTÃO, 2015).

No outro extremo, o narrador do livro faz a gestão do desenrolar narrativo de modo a dar ênfase ao passo a passo dos fatos, ao "miudinho" de seu desenrolar: "O senhor espere o meu contado. Não convém a gente levantar escândalo de começo, só aos poucos é que o escuro é claro" (ROSA, 1986, p. 165).

O que está em jogo nesse embate rítmico é algo muito recorrente na interação entre literatura e quadrinhos. Isso porque há uma práxis cristalizada na reiteração de um modo de enunciar que estabelece algumas estratégias consagradas de enunciação dos quadrinhos, em que se cria uma dinâmica de leitura ágil. Ao levantarmos características como simultaneidade do visual e do verbal; a ampla potencialidade do uso dos requadros, que faz Eisner (2010) dizer que há uma verdadeira "linguagem do requadro" agregando camadas de leitura; a elipse como elemento de identidade dos quadrinhos; a quantidade de quadros e o modo de distribuí-los espacialmente, que além dos seus diferentes tamanhos e formatos, podem (ou não) dividir a página em uma quantidade variada de ações e guiar o sentido e a sequencialidade (ou a ruptura) da leitura; esses elementos, tomados em sua totalidade, determinam uma expectativa do modo de interação entre quadrinhos e outras linguagens, além de um modo de engajamento sensível pautado por um elã da rapidez dos quadrinhos (MANCINI; ALT, 2013).

Em linha com Will Eisner (2010, p. 1) ao dizer que "quando se examina uma obra em quadrinhos como um todo, a disposição de seus elementos específicos assume a característica de 'linguagem", a proposta é a de que a prática semiótica, enquanto gesto enunciativo, quando reiterada em uma práxis enunciativa (FONTANILLE; ZILBERBERG, 2001), estabiliza e cristaliza em um tempo coletivo, um modo prototípico de dispor expressão e conteúdo, que se sedimenta numa "linguagem".

A linguagem dos quadrinhos, assim entendida, prevê de antemão uma agilidade que acaba por se colocar como força de coerção que molda as escolhas do 
adaptador da literatura para quadrinhos, que se vê impelido seja a fazer sínteses, seja a privilegiar partes específicas da obra de partida a ser adaptada. Síntese ou triagem de partes passam a ser as duas estratégias principais que definem um gesto a priori do adaptador da literatura para quadrinhos.

Lembremos que o adaptador aqui é enunciatário da obra de partida, cujo fazer interpretativo em relação ao romance guiará as escolhas das estratégias que utilizará para dar corpo à HQ. No caso específico dessa adaptação, o enunciador (congregado nas escolhas conjuntas do roteiro de Guazzelli e da arte de Rosa), optou, prioritariamente, pela sintese.

Do ponto de vista das estratégias de conteúdo, a opção foi por manter as mesmas figuras ${ }^{5}$, como no caso da caracterização dos jagunços, das paisagens do sertão, que, assim como no romance, na HQ ocupa um lugar de destaque.

Sobre o foco narrativo, a mesma teia narrativa foi mantida nas duas obras, inclusive com a mesma hierarquia dos programas narrativos ${ }^{6}$ da obra de partida.

O olhar de Riobaldo e sua narrativa amorosa, que acaba por ser também uma narrativa identitária, desenha o arco geral em torno ou a partir do qual todos os outros programas narrativos se organizam. A diferença do romance para a HQ é que a quantidade de programas coadjuvantes, que no romance vão traçando uma teia intrincada e densa de sujeitos, suas metas, suas motivações, seus ajudantes e seus obstáculos - no jargão semiótico, sujeito, objeto-valor, destinador, adjuvante e antissujeito, respectivamente -, na versão em quadrinhos, essa vereda narrativa se abre em poucos programas, escolhidos com muita perspicácia para que não se desfizesse a maleabilização axiológica original que faz esmaecer a separação nítida entre o bem e o mal.

Assim, temos o programa narrativo de Joca Ramiro (sujeito) e seus comparsas (adjuvantes) contra Zé Bebelo (antissujeito), representante do governo que perde a batalha. Joca Ramiro, figurativizado como um homem leal e ponderado, em sua sanção, faz um julgamento justo e liberta Zé Bebelo. Com isso, provoca a ira de seus comparsas, Hermógenes e Ricardão, que, posteriormente em um episódio de traição, matam Joca Ramiro em uma nova batalha.

É interessante notar a inversão das posições actanciais. Quem era adjuvante, virou antissujeito. Quem era antissujeito, virou adjuvante do mesmo sujeito Joca Ramiro. Essa alternância na estrutura narrativa é umas das estratégias do enunciador do livro que foi transportada para os quadrinhos quando esses programas narrativos são escolhidos, dentre outros, para compor a versão da HQ. A intercambialidade, na estrutura narrativa, entre quem ajuda e quem obstacula, espelha uma complexidade temática que irradia por toda a obra, romance ou HQ, e que tem seu epicentro na figura do diabo "no meio do redemoinho".

Coerente com essa estrutura, não é por acaso que quando Riobaldo faz o pacto com o diabo, ele consegue fazer "o bem". Essa ambiguidade - terreno movediço que desestabiliza os polos - construída desde os estratos mais profundos

5 "Podem-se revestir os esquemas narrativos abstratos com temas e produzir um discurso não figurativo ou podem-se, depois de recobrir os elementos narrativos com temas, concretizá-los ainda mais, revestindo-os com figuras. Assim, tematização e figurativização são dois níveis de concretização do sentido [...]. No entanto, é preciso ter em mente que concreto e abstrato não são termos polares que se opõem de maneira absoluta, mas constituem um continuum em que se vai, de maneira gradual, do mais abstrato ao mais concreto" (FIORIN, 2011, p. 90-91).

6 "A semiótica parte dessa visão espetacular da sintaxe e propõe duas concepções complementares de narrativa: narrativa como mudança de estados, operado pelo fazer transformador de um sujeito que age no e sobre o mundo em busca dos valores investidos nos objetos; narrativa como sucessão de estabelecimentos e de rupturas de contratos entre um destinador e um destinatário, de que decorrem a comunicação e os conflitos entre sujeitos e a circulação de objetos. As estruturas narrativas simulam, por conseguinte, tanto a história do homem em busca de valores ou à procura de sentido quanto a dos contratos e dos conflitos que marcam os relacionamentos humanos" (BARROS, 1999, p. 16). 
de ambas as obras, é sintetizada na célebre passagem: "Viver é muito perigoso... Querer bem com demais força, de incerto jeito, pode já estar sendo se querendo o mal por principiar" (ROSA, 1986, p. 9).

Um novo programa narrativo se inicia, em que Zé Bebelo, o opositor de Joca Ramiro na primeira narrativa, passa a ser o sujeito que vai operar sua vingança. As escolhas do enunciador da HQ de dar lugar de destaque a essas narrativas, por conta da síntese prevista pela coerção de agilidade da linguagem dos quadrinhos, acaba por deixar mais claro esse bordado narrativo em favor da complexificação dos polos bem e mal, essa dimensão essencial da obra de partida.

Do ponto de vista da adesão do leitor, a trama densa de muitos programas dentro de programas do livro constrói as veredas narrativas que levam o leitor a um estado de indefinição contínua, uma exacerbação sensivel por não conseguir estabilizar os polos. Na HQ, esse efeito é minimizado com a redução dos programas narrativos apresentados, por conta da coerção da agilidade de leitura, como já mencionamos. Com isso, na HQ o leitor consegue "ver" melhor a trama, entende com mais clareza os liames pela perspectiva mais geral da sintese narrativa.

No entanto, para compensar isso que seria um enfraquecimento da interface sensivel, em favor da inteligibilidade narrativa, o enunciador se encarrega de trazer essa exacerbação sensivel de volta com estratégias da expressão. Para falar em linhas gerais, lança mão de uma pluralidade de tipos e tamanhos de quadros, divisão e disposição dos quadros na página irregular, desreferencialização do espaço da ação pelo uso de closes e perspectivas inusitadas, alternância de paletas cromáticas em momentos de alta tensão, como em dois casos que no romance são pontos de pico de intensidade e, portanto, visam criar saliências perceptivas: a morte de Joca Ramiro e a subsequente descoberta de que ele era pai de Diadorim; a morte do jagunço Diadorim e subsequente descoberta de que ele era, de fato, uma mulher.

Figura 1 - Diadorim descobre que seu pai, Joca Ramiro, está morto

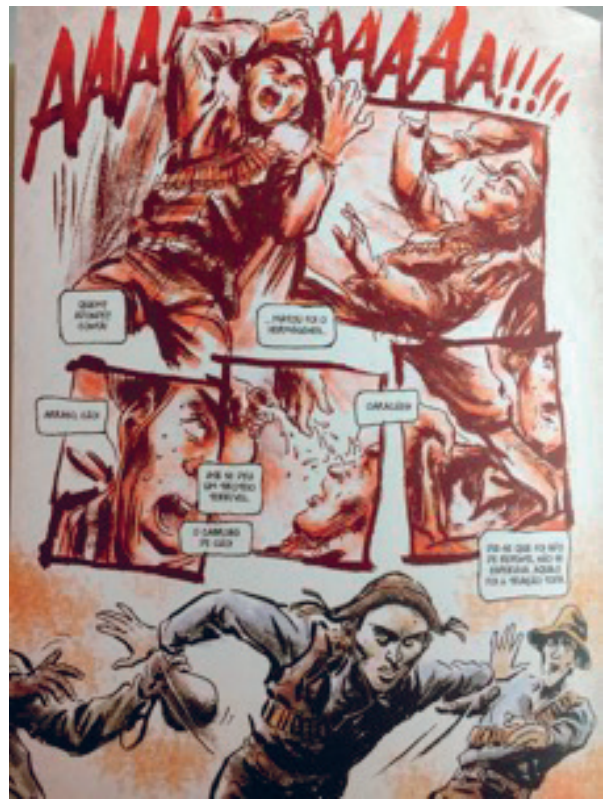

Fonte: Rosa e Guazzelli (2014, p. 92). 
Figura 2 - Momento da morte de Diadorim

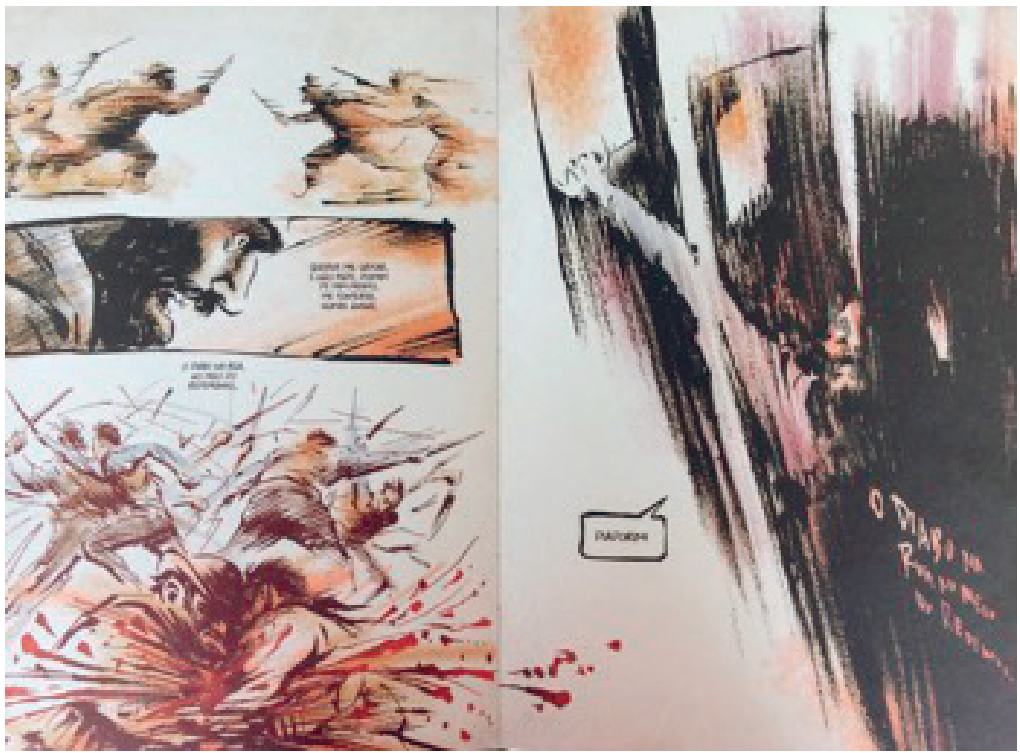

Fonte: Rosa e Guazzelli (2014, p. 154-155).

A descoberta de que Diadorim é uma mulher configura o momento de maior intensidade de ambas as obras. É o pico de saliência sensivel do arco tensivo. É onde se abre espaço para a lógica concessiva, o ápice da força de ruptura de um caminho que, até aquele ponto, não dava sinais de previsibilidade para esse desfecho. A tensão criada pela ambivalência sexual e afetiva entre Riobaldo e Diadorim sustenta a obra e se desfaz, abruptamente, neste momento, em concomitância com a morte de um dos actantes da narrativa principal, a narrativa amorosa. É um impacto forte que sensibiliza o leitor, que se despede da obra tomado por uma sensação de vertigem.

Figura 3 - Momento da descoberta de que Diadorim é mulher

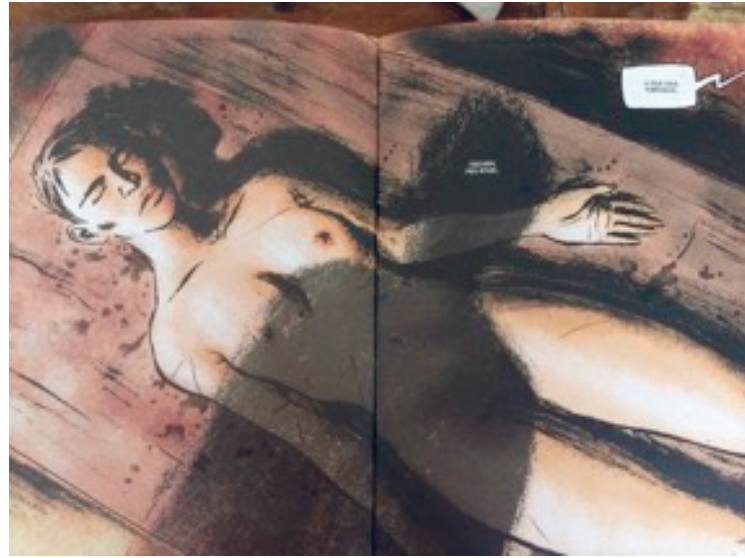

Fonte: Rosa e Guazzelli (2014, p. 160-161). 
DOSSIE

Figura 4 - Momento imediatamente posterior à descoberta de que Diadorim é uma mulher

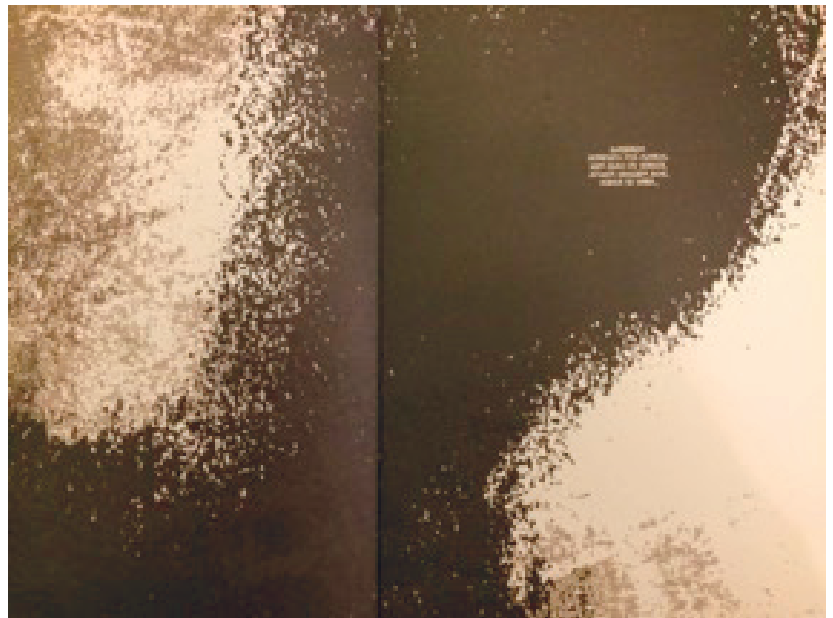

Fonte: Rosa e Guazzelli (2014, p. 164-165).

A construção do caminho que culmina nessa quebra tônica de expectativa, nessa concessão forte ao final, se dá pelo hábil jogo de perspectivas de que falamos no início. Toda a tensão amorosa/sexual entre Riobaldo e Diadorim, o fio responsável por amarrar o arco da obra, é criada a partir dos pontos de vista do narrador Riobaldo e do personagem (interlocutor) Riobaldo sincretizados em uma mesma voz, o que suspende a demarcação nítida entre o narrado pela perspectiva do já conhecido e pela perspectiva da vivência no miudinho dos fatos, como explicamos.

$\mathrm{Na}$ versão em quadrinhos, essa tensão contínua entre os pontos de vista é mantida, de modo hábil, como ilustramos com os exemplos a seguir:

Figura 5 - Sincretismo das vozes narrador/personagem construído verbo-visualmente

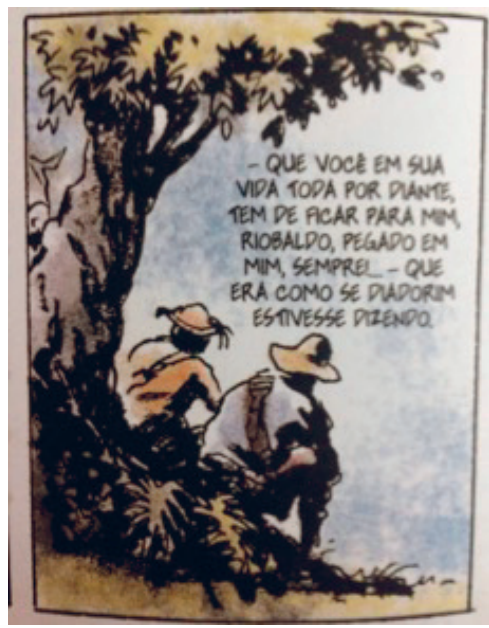

Fonte: Rosa e Guazzelli (2014, p. 86). 
Na Figura 5, se por um lado o uso do travessão indica a fala, primeiro de Diadorim, para depois definir-se como a fala de Riobaldo, também marcada por um travessão interno, propondo um simulacro de fala para Diadorim, por outro, ter essa fala solta na página, sem balão, cria uma tensão sobre quem está falando de fato (ambos Riobaldo e Diadorim; só Riobaldo; Riobaldo e o narrador ao mesmo tempo; só o narrador, pois o travessão indicaria um simulacro de fala), todos ou ninguém, neste caso, num silêncio denso construído pela indeterminação das vozes em torno da tensão amorosa... os personagens de costa, vistos a uma certa distância, aumentam essa ambivalência do jogo de vozes.

Figura 6 - Sincretismo das vozes narrador/personagem construído verbo-visualmente

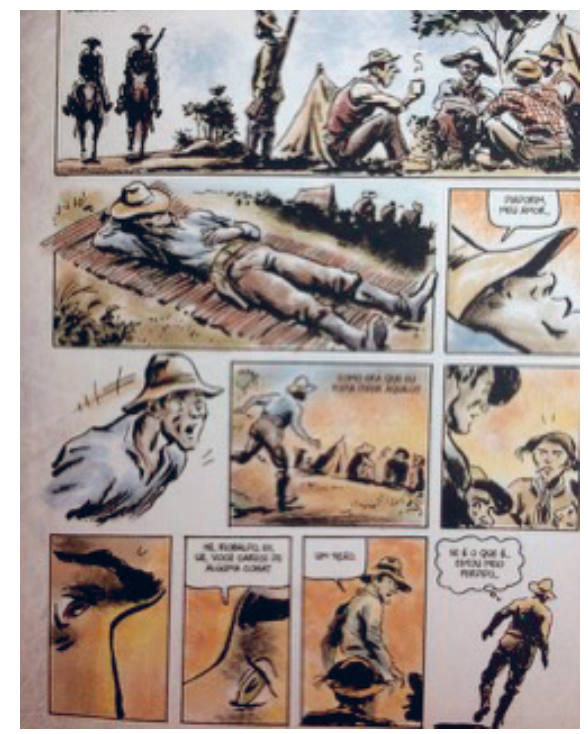

Fonte: Rosa e Guazzelli (2014, p. 87).

Na Figura 6, vale ressaltar que o sincretismo se dá na passagem "Como é que eu podia pensar aquilo", fala que pode ser atribuída ao narrador Riobaldo e ao personagem Riobaldo ao mesmo tempo.

O fechamento de Grande sertão: veredas em quadrinhos indica a sensibilidade desse enunciador que reúne em si as estratégias de roteiro e arte. A fala final de Riobaldo, no romance, é esgarçada e desdobrada em algumas páginas nos quadrinhos, trazendo em primeira mão ao enunciatário aquilo que parece ser a sintese do argumento da obra: uma exaltação do devir, a tensão do movimento, que, como tal, tem direção, mas nunca se estabiliza em polos demarcados, claros, estanques. É precisamente no hiato entre polos criado pelo movimento que se abre o lugar instável onde a vida pulsa.

Amável o senhor me ouviu, minha ideia confirmou: que o Diabo não existe. Pois não? $O$ senhor é homem soberano, circunspecto. Amigos somos. Nonada. $O$ diabo não há! É o que eu digo, se for... Existe é homem humano. Travessia (ROSA, 1986, p. 538). 


\section{The READER ENGAGEMENT MODES IN THE COMIC GRANDE SERTÃo: VEREDAS}

Abstract: The universe founded by the work Grande sertão: veredas, by Guimarães Rosa, and its place of landmark in Brazilian literature make the project of his comic adaptation an adventure that arouses attention and curiosity. What are the paths to be taken for the construction of the script and what are the solutions found to recreate, in general or in part, the enunciative project of this compelling work? We propose the analysis of its adaptation to comics of the same title by Rodrigo Rosa (art) and Eloar Guazzelli (screenplay). We aim to explain some strategies and choices of the adapters, in order to better understand the effects of meaning sought in the comic book in its relation with the novel.

Keywords: Grande sertão: veredas. Intersemiotic translation. Comics language.

\section{REFERÊNCIAS}

BARBIERI, D. As linguagens dos quadrinhos. São Paulo: Peirópolis, 2017.

BARROS, D. P. L. de. Teoria semiótica do texto. São Paulo: Editora Ática, 1999. DISCINI, N. Entre interações de risco e tensões do afeto. Galáxia - Revista do programa de pós-graduação em comunicação e semiótica, São Paulo, v. 1, n. 36, dez. 2017, p. 85-98. Disponivel em: https://revistas.pucsp.br/galaxia/article/ view/32733. Acesso em: 9 abr. 2019.

EISNER, W. Quadrinhos e arte sequencial. 4. ed. São Paulo: Martins Fontes, 2010. FIORIN, J. L. As astúcias da enunciação: as categorias de pessoa, espaço e tempo. São Paulo: Ática, 1999.

FIORIN, J. L. Elementos de análise do discurso. São Paulo: Editora Contexto, 2011.

FONTANILlE, J.; ZILBERBERG, C. Tensão e significação. Tradução de Ivã Carlos Lopes, Luiz Tatit e Waldir Beividas. São Paulo: Discurso Editorial: Humanitas / FFLCH/USP, 2001.

GRANDE SERTÃO: veredas em HQ. Conta uma história, 6 fev. 2015. Disponível em: http://contaumahistoria.com.br/2015/02/grande-sertao-veredas-em-hq/. Acesso em: 9 abr. 2019.

GREIMAS, A. J. Sobre o sentido II: ensaios semióticos. São Paulo: Nankin, Edusp, 2014.

GREIMAS, A. J.; COURTÉS, J. Dicionário de semiótica. São Paulo: Contexto, 2008.

GROENSTEEN, T. O sistema dos quadrinhos. Tradução Érico Assis e Francisca Ysabelle Manriquez Reyes. Nova Iguaçu: Marsupial Editora, 2015.

HJELMSLEV, L. Prolegômenos a uma teoria da linguagem. São Paulo: Perspectiva, 1975.

MANCINI, R.; ALT, J. Quadrinhos: do papel à internet. In: TEIXEIRA, L.; CARMO JR., J. R. do (org.). Linguagens na cibercultura. São Paulo: Estação das Letras e Cores, 2013. 
McCLOUD, S. Desenhando quadrinhos. São Paulo: MBooks, 2008.

ROSA, G. Grande sertão: veredas. Rio de Janeiro: Nova Fronteira, 1986.

ROSA, R.; GUAZELLI, E. Grande sertão: veredas (adaptação da obra homônima de ROSA, G. para quadrinhos). São Paulo: Biblioteca Azul, 2014.

ZILBERBERG, C. Síntese da gramática tensiva. Significação: Revista de Cultura Audiovisual, v. 33, n. 25, p. 163-204, 23 jun. 2006. Disponivel em: http://www. revistas.usp.br/significacao/article/view/65626. Acesso em: 9 abr. 2019.

ZILBERBERG, C. Louvando o acontecimento. Galáxia. Revista do Programa de Pós-Graduação em Comunicação e Semiótica, n. 13, p. 13-28, out. 2007. Disponivel em: https://revistas.pucsp.br/galaxia/article/view/1472. Acesso em: 9 abr. 2019.

ZILBERBERG, C. Elementos de semiótica tensiva. São Paulo: Ateliê Editorial, 2011.

Recebido em 23 de fevereiro de 2019 Aprovado em 23 de março de 2019. 